\title{
Happy 70, Archives! - our mission and vision for the years to come
}

\author{
Dado Čakalo and Nevenka Kopjar \\ Institute for Medical Research and Occupational Health, Zagreb, Croatia
}

This year we turn 70! Lucky for journals, they don't get old with volumes. In our case, quite the opposite. The idea of this editorial, however, is not to look so far back but to share with you - our readers and authors - where we see Archives in the years to come.

KEY WORDS: cOalition S; narrative, open access; quality; peer review; Plan S; reader first

Over the last ten years, we decided that our mission were three things: high visibility, open access, and quality (1). We are highly visible through our online outlets (De Gruyter's Sciendo platform and the Croatian repository of scientific journals Hrčak) and eminent indexing databases such as Clarivate's Web of Science, Scopus, PubMed, and EBSCO, to name a few. Our impact factor is stable above 1 and rising. Open access we've always held very dear: we've never charged our online readers nor have we charged our authors. And as for quality, this is an ongoing mission. We seek to help our authors publish what we think is worth publishing through free editing and publishing services. But we also reject about $70 \%$ of submissions. We have a strict plagiarism policy in place and screen all submissions through CrossRef's Similarity Check service, yet before we make any decisions based on similarity reports, we evaluate the potential of submitted manuscripts. Machines can not replace humans in that respect. We have also fostered the idea that less is more. Quality over quantity, if you please. In a nutshell, over the last ten years, we've been focused on our readers (first) and our authors as our greatest valuables.

And we intend to stick to our mission and take it a step further. In terms of visibility, we intend to have our full-text articles available on PubMed Central as soon as we figure out technical issues related to XML-coding. We also intend to expand in publication formats so that they are more responsive and interactive than now.

As for open access, we strongly support the Plan S initiative (2) by the cOALition $\mathrm{S}$ that reporting on all publicly funded research is available to the public who's funding it for free by 2020. After all, this is what we've

Corresponding author: Dado Čakalo, Editorial Office of Archives of Industrial Hygiene and Toxicology, Institute for Medical Research and Occupational Health, Ksaverska cesta 2, 10000 Zagreb, Croatia

E-mail:dcakalo@imi.hrorarhiv@imi.hr been doing all along. But what about public funding of journals? The noble idea of making free peer reviewed quality outlets available for researchers seems to have withered and died over the last couple of years. Science journals in Croatia, for example, can no longer really count on government subsidies that had kept us going. Even the Plan S has lost sight of the option that perhaps it would be wise to fund the existing European open access journals that do not charge publication fees to authors and their institutions instead of setting up new ones (see point 4 of Guidance on the Implementation of Plan S) (3). In other words, access may be open to readers, but not to all authors and their institutions. What about authors from non-EU countries? Big publishing industry will survive, though, thrive even. We therefore invite our authors and readers to share their thoughts with us about this huge issue and propose a way out of the conundrum. Unless we find a solution for small yet valuable open access journals that do not charge authors, they will have to shift to the author-pay model. Not good at all!

Quality has always been our primary concern. As a small journal we seldom get the top-rated, Nature-type research or review articles, but we can definitely do our best to make presentation better - for the reader's sake. In the years to come, we therefore intend to insist with authors on two things: to make it perfectly clear why they consider their research and writing about it new and/or important and, if we are convinced, to help them with the narrative. Articles should never be boring to read is what we believe. If you think that we are forgetting something along these lines, we are not. Ahead of us we have another great battle to fight: improve the quality of peer reviews. This issue has become overwhelming with the hyperproduction of research papers. But not only do journals have problems finding reliable peer reviewers; authors also have a problem finding journals that can provide relatively fast quality peer review. We often struggle with superficial peer reviews, 
which then trigger a cascade of new review requests until we get useful feedback. We therefore support initiatives such as SciRev (4), where researchers share their experiences with journals, and will do our best to improve our peer review process in terms of efficacy, quality, and transparency. Luckily, we still have a number of enthusiastic, quality peer reviewers, to whom we thank with all our heart at the end of this issue (see Acknowledgment to Referees, p. A1).

We invite all of you, our readers, authors, and peer reviewers to share your opinions and help us all get better.

\section{REFERENCES}

1. Čakalo D. Archives of Industrial Hygiene and Toxicology: your local grocer online. Eur Sci Edit 2014;44:63-4.

2. cOALition S. About Plan S [displayed 19 March 2019]. Available at https://www.coalition-s.org/

3. cOALition S. Guidance on the Implementation of Plan S [displayed 19 March 2019]. Available at https://www. coalition-s.org/implementation/

4. SciRev Foundation. Background [displayed 19 March 2019]. Available at: https://scirev.org/ 